\title{
Morphological identification of adult male Haemonchus species in goats from Thailand and Lao PDR
}

\author{
Vongnady, K. ${ }^{1}$, Rucksaken, R. ${ }^{1}$ and Mangkit, B. ${ }^{*}$ \\ ${ }^{1}$ Department of Veterinary Technology, Faculty of Veterinary Technology, Kasetsart University, \\ Bangkhen Campus, Bangkok 10900, Thailand \\ *Corresponding author e-mail: fvetbdm@ku.ac.th \\ Received 24 March 2020; received in revised form 8 July 2020; accepted 8 July 2020
}

\begin{abstract}
Haemonchus spp. or barber's pole worms are one of the most highly pathogenic nematodes of ruminants causing economic losses in livestock worldwide. The current study was a first attempt to identify Haemonchus spp. from goats in Thailand and Lao PDR. Utilizing the inexpensive tools of the discriminant function (DF) combined with synlophe patterns is fundamental for understanding their epidemiological aspects. In total, 255 randomly chosen adult male Haemonchus worms from goats in various areas in each country were identified individually. For both these countries, about $94 \%$ based on the DF values, and 99\%, $98 \%$, and $97 \%$ based on synlophe patterns in the region of the esophageal intestinal junction (EI), $4 \mathrm{~mm}$ from the anterior end, and at both these positions, respectively, were identified as $H$. contortus. Other identified specimens defined as H. placei and hybrids as well as unclassified species based on synlophe patterns were proved using polymerase chain reaction (PCR); this also included some randomly chosen $H$. contortus by DF and synlophe patterns. All those specimens were confirmed as $H$. contortus being strongly supported by some genetic evidences and UPGMA analysis. Thus, it was assumed that all specimens in the current study were $H$. contortus. The morphological differences of this predominant species (H. contortus) in goats between the two countries were: body length, gubernaculum length, and left spicule barb length, while almost all characters of male worms individually measured appeared to overlap, mostly in $H$. contortus and $H$. placei, which may lead to misclassification. Therefore, using the DF along with synlophe patterns can assist in increasing the accuracy of Haemonchus spp. identification from goats in some areas where funding is limited, particularly in Lao PDR. The present results revealed that synlophe patterns in the EI region seemed to be promising for the identification of Haemonchus spp., while molecular techniques are also required to address ambiguous identification with some specimens.
\end{abstract}

\section{INTRODUCTION}

Haemonchus spp. commonly recognized as barber's pole worm, cause haemonchosis and are found in the abomasa of large and small ruminants worldwide (Lichtenfels \& Pilitt, 2000; Achi et al., 2003). Two major species have the greatest veterinary importance, namely Haemonchus contortus and Haemonchus placei. H. contortus is normally found in goats and sheep while H. place $i$ is known to be a parasite of cattle (Lichtenfels et al., 1994). H. contortus is the most pathogenic of the common nematodes, particularly in young animals (Hoberg et al.,
2004) and its blood-feeding behavior results in severe anemia and weight loss, with death eventually occurring in cases of heavy infection (Besier et al., 2016). These outcomes lead to a reduction in animal production and increase production costs, causing huge economic losses worldwide (Stevenson et al., 1995; Waller \& Chandrawathani, 2005; Wang et al., 2017; Sallé et al., 2019). For example, in endemic areas of Australia, the mean annual cost due to $H$. contortus causing ewe death accounted for AUS 11/head, including treatment and cost of diagnosis (Besier et $a l .$, 2016). In Thailand and Lao PDR, goat 
production is currently increasing, mostly due to smallholders as a means of generating income for local people, where haemonchosis in small ruminants such as goats caused by Haemonchus spp. including $H$. contortus seems to be a regular problem since the main strategies for parasite control are probably not effective as a consequence of drug resistance (Waller et al., 2004; Waller \& Chandrawathani, 2005; Pralomka \& Boonsanit, 2012; Sallé et al., 2019) and the ability of parasites that can adapt to variable environments in temperate and tropical climates (Troell et al., 2006). Although the losses due to the impacts of this parasite have not been officially recorded in both countries, this parasitic infection in Thailand (Laosutthipong \& Eardmusic, 2019) and Lao PDR (Sato et al., 2014) has also been continually associated with a high infection rate (86.67\% and 69\%, respectively).

An accurate identification of Haemonchus spp. distributed in goats will help to understand their epidemiological picture, current status, and can also be applied to support effective parasite control (Jacquiet et al., 1995; Silva et al., 2015). Using a traditional method such as stool examination to examine the parasite's egg is of limited value, since the morphology of their eggs is somewhat similar to that of other strongyle nematodes and hence is difficult to differentiate (Valderrabano et al., 2002) while identification of the infective larval stage via the fecal culture technique is useful for species identification, but is time-consuming and should be performed by scientific experts (Waller et al., 2004; Besier et al., 2016). A discriminant function (DF) combining the measurements of adult male Hamonchus spp. based on spicule length and spicule barb length is a rapid, easy and reliable tool (Achi et al., 2003; Amarante, 2011; Gharamah et al., 2011) that is commonly used to identified the three main Haemonchus spp. (H. contortus, $H$. place $i$ and $H$. similis) occurring in naturally infected goats and sheep (Le Jambre \& Whitlock, 1968; Jacquiet et al., 1995; Achi et al., 2003; Kumsa et al., 2008; Gharamah et al., 2011; Santos et al., 2014; Vadlejch et al., 2014) while synlophe or cuticular ridge patterns presenting on the body of parasite are one of the most useful characters used for identifying male and female Haemonchus spp. (Lichtenfels et al., 1994; Lichtenfels \& Pilitt, 2000) and also has been applied for the identification of Haemonchus spp. in various areas, namely the United States (Lichtenfels et al., 1986), Malaysia (Rahman \& Abd Hamid, 2007; Gharamah et al., 2011), and Brazil (Silva et al., 2015). Moreover, in some situations when the spicule measurements have overlapping values between $H$. place $i$ and $H$. contortus, the synlophe patterns can facilitate identification (Amarante, 2011). Molecular methods of which polymerase chain reaction (PCR) is one of the most advanced techniques are more rapid, and have high sensitivity and specificity for identifying worms with high certainty, including Haemonchus spp. (Roeber et al., 2011). However, the high cost of such techniques is a disadvantage (Comes et al., 1996; Achi et al., 2003; Gharamah et $a l ., 2011$ ), and these techniques might not be suitable for routine use, particularly in some developing countries where budgets are limited.

This was the first study to attempt to apply useful traditional methods as a low cost diagnosis based on morphological characters to identify adult male Haemonchus spp. in goats obtained from Thailand and neighboring Lao PDR, where advanced technologies such as PCR and also financial support are still restricted while haemonchosis in goats in both countries seems to be seriously affecting animal health and decreasing goat production. Thus, the aim of this research was to identify adult male Haemonchus spp. in infected goats collected from different areas in Thailand and Lao PDR by using a discriminant function (DF) combined with cuticular ridge patterns. PCR using the ITS2 region, a low intravariation of ribosomal DNA (rDNA) was used to identify and confirm Haemonchus spp. in some cases (Stevenson et al., 1995; Gasser \& Newton, 2000) with consideration of some basic genetic and phylogenetic data. Moreover, measurements of common morphological characters of predominant Haemonchus spp. were recorded and 
compared, consisting of: total body length, cervical papillae, esophagus length, right and left spicule lengths, right and left spicule barb lengths and gubernaculum length. The significance of the distribution of known species of Haemonchus spp. in each country from this research will lead to improved strategies for parasite control and a future prevention program.

\section{MATERIALS AND METHODS}

\section{Study area, animal hosts, and parasites}

Adult male Haemonchus spp. were collected from the abomasa of goats in different local slaughterhouses in different geographical zones of Thailand and Lao PDR during the period from June to July 2019 (Figure 1). Most goats included in this research in Thailand were mixed breed while almost all animals in Lao PDR were native goats. Goats showed some possible clinical signs such as poor overall body condition, emaciation and loss of hair or rough hair coat were selected primarily for this investigation. Three different provinces of each country were chosen based on geographical distance apart (more than $500 \mathrm{~km}$ and $250 \mathrm{~km}$ in Thailand and Lao PDR, respectively) with high animal populations including there was scanty information of Haemonchus spp. in goats. In Thailand, the three provinces selected in the northern, central, and southern regions were Chiang Rai $\left(19^{\circ} 54^{\prime} 30.89^{\prime \prime} \mathrm{N}\right.$ and $\left.99^{\circ} 49^{\prime} 57.00^{\prime \prime} \mathrm{E}\right)$, Chai Nat $\left(15^{\circ} 11^{\prime} 3.60^{\prime \prime} \mathrm{N}\right.$ and $\left.100^{\circ} 07^{\prime} 17.40^{\prime \prime} \mathrm{E}\right)$ and Nakhon Sri Thammarat $\left(8^{\circ} 26^{\prime} 6.59^{\prime \prime} \mathrm{N}\right.$ and $\left.99^{\circ} 57^{\prime} 28.19^{\prime \prime} \mathrm{E}\right)$, respectively. For Lao PDR, Luang Prabang province $\left(19^{\circ} 53^{\prime} 21.3756^{\prime \prime} \mathrm{N}\right.$ and $\left.102^{\circ} 8^{\prime} 0.4308^{\prime \prime} \mathrm{E}\right)$ Savannakhet province $\left(16^{\circ} 32^{\prime} 59.99^{\prime \prime} \mathrm{N}\right.$ and $\left.104^{\circ} 44^{\prime} 59.99^{\prime \prime} \mathrm{E}\right)$ and Champasak province $\left(15^{\circ} 6^{\prime} 37.8252^{\prime \prime} \mathrm{N}\right.$ and $\left.105^{\circ} 49^{\prime} 2.2476^{\prime \prime} \mathrm{E}\right)$ located in the northern, central, and southern regions, respectively, were chosen.

Thirty and 68 infected goats from Thailand and Lao PDR were detected from 63 and 103 goats, respectively. The collected adult male worms from the abomasa were collected with modifications to Soulsby (1982) and MAFF (1971). The abomasa were opened and the contents inside were sieved and washed carefully with tap water. Then, the parasites were carefully collected and placed in a clean petri dish containing $0.85 \%$ normal saline. Adult male parasites obtained from individual hosts were washed three times with this physiological saline prior to fixing in $70 \%$ ethanol and storing at $-20^{\circ} \mathrm{C}$ for further study.

\section{Morphological characterization and species identification}

Individual adult males of Haemonchus spp. were randomly selected from infected individual hosts in each province of Thailand and Lao PDR, with 255 adult male worms (85 worms/province) in each country being used. First, the posterior end of each worm was cut above the bursa to measure the spicule length (right: RSL and left: LSL), the tip to the hook of right and left spicule barbs (right: THr and left: THl), and the gubernaculum (GL) (Figure 2). Finally, synlophe patterns were cut in cross section at two main positions, namely the esophageal-intestinal junction (EI) and $4 \mathrm{~mm}$ from the anterior end. All measurements such as cervical papillae, esophagus length, and etc. were carried out under light microscopy at 40x/50x, 100x and 400x magnification (Olympus Corporation, Tokyo, Japan; Carl Zeiss Microscopy GmbH, Jena, Germany) except for the body length which was measured using stereomicroscopy (Olympus Corporation, Tokyo, Japan).

The discriminant function (DF) described by Jacquiet et al. (1997) and Achi et al. (2003) comprising three main parameters of male worms-TL (mean), THr, and THl was calculated using the formula:

$\mathrm{DF}=0.0016 \mathrm{TL}+0.128 \mathrm{THr}+0.152 \mathrm{THl}-9.97$

Identification of Haemonchus spp. based on the DF value was classified into three categories: $\mathrm{DF}<0.63=H$. contortus $; 0.63<$ $\mathrm{DF}<3=H$. place $i$ DF $>4=H$. similis.

Observations of synlophe patterns in all adult male worms of Haemonchus spp. from both countries were conducted according to the procedure described by Lichtenfels et al. (1994) and Vongnady et al. (2020). Briefly, all specimens were cut on cross section at the level of the EI region and $4 \mathrm{~mm}$ from the 


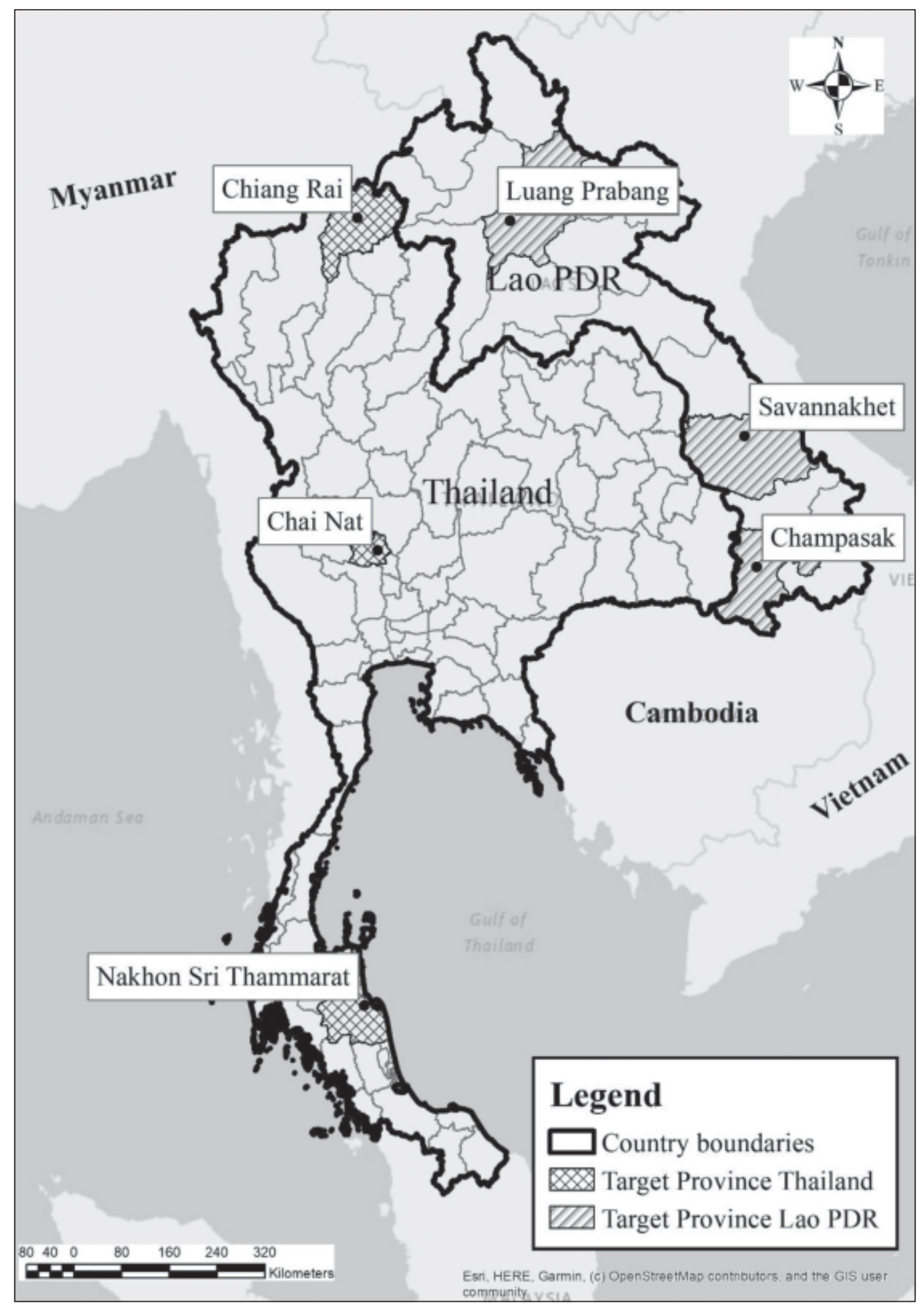

Figure 1. Sampling locations of Haemonchus spp. in goats from Thailand and Lao PDR. 


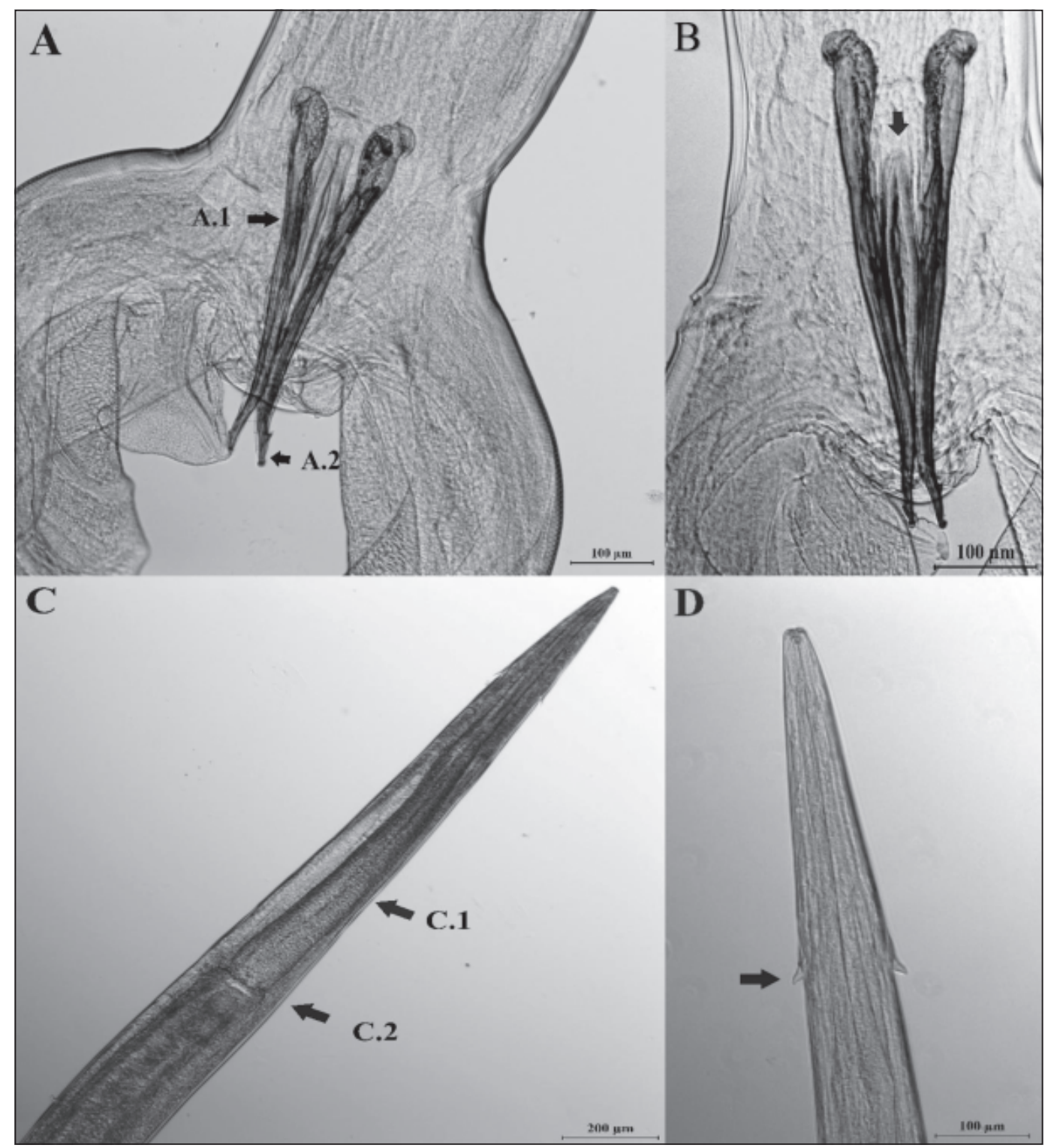

Figure 2. Some morphological characters of adult male Haemonchus spp. in goats from Thailand and Lao PDR used for species identification: (A) A.1, right/left spicules; A.2, right/left spicule barbs; (B) gubernaculum; (C) C.1, esophagus; C.2, esophageal intestinal junction; (D) cervical papillae.

anterior end using a freehand cut with a shape razor blade. These cross sections were mounted in glycerin jelly and left about $5 \mathrm{~min}$ before viewing and counting the number of cuticular ridges under a light microscope at 100x and 400x magnification. Identification of Haemonchus spp. using the synlophe patterns was based on three main researcher references, with the synlophe patterns at the EI region of H. contortus, H. place $i$ and $H$. similis having 30,34 and 34 ridges, respectively, (Lichtenfels et al., 1994; Silva et al., 2015) while at $4 \mathrm{~mm}$, there were 30 ridges for each of $H$. placei and H. similis (Lichtenfels et al., 1994) as well as $H$. contortus having 25 ridges (Lichtenfels $e t$ $a l ., 1994)$ and 24 and 26 ridges (Rahman \& Abd Hamid, 2007). 


\section{Molecular identification}

\section{DNA extraction}

Only 24 and 26 adult male worms from Thailand (Table 2) and Lao PDR (Table 3), respectively, were used for DNA isolation. These specimens derived from $H$. placei and hybrids that were identified using the DF, including unclassified species based on synlophe patterns at both positions as well as four worms in Thailand and eight worms in Lao PDR that were identified as $H$. contortus using the DF value and synlophe patterns. The rest of the parasite body from morphological characterization was extracted for genomic DNA using a DNA commercial tissue kit GF-1 Tissue DNA Extraction Kit (Vivantis Technologies Sdn, Bhd, Selangor Darul Ehsan, Malaysia). The procedure was carried out according to the manufacturer's instructions. Briefly, the remaining parts of each whole male worm were transferred to a $1.5 \mathrm{~mL}$ microcentrifuge tube. The parasite tissues were mechanically ground and with $250 \mu \mathrm{L}$ of lysis buffer, and then $20 \mu \mathrm{L}$ of proteinase $\mathrm{K}$ with $12 \mu \mathrm{L}$ of lysis enhancer were added. The homogeneous mixture was incubated at $65^{\circ} \mathrm{C}$ for $90 \mathrm{~min}$. After added binding buffer, this homogeneous mixture was incubated at $65^{\circ} \mathrm{C}$ for $10 \mathrm{~min}$. The purified DNA binding on the membrane was eluted in elution buffer. The concentration of eluted DNA was measured using the NanoDrop procedure (Thermo Fisher Scientific, Wilmington, USA) and stored at $-20^{\circ} \mathrm{C}$ until used.

\section{PCR amplification and DNA sequencing}

The ribosomal DNA internal transcribed spacer 2 (ITS2) region was amplified with specific primer sets described by Stevenson et al. (1995). PCR reaction reported by Vongnady et al. (2020) was prepared in a total volume of $20 \mu \mathrm{L}$ containing 10X Taq Buffer with (NH4) ${ }_{2} \mathrm{SO}_{4}, 5 \mathrm{mM}$ of each dNTPs, $25 \mathrm{mM}$ $\mathrm{MgCl}_{2}, 10 \mu \mathrm{M}$ of each primer, $1.25 \mathrm{U} / \mu \mathrm{L}$ of Taq DNA polymerase (Thermo Fisher Scientific, Wilmington, USA) and $2 \mu \mathrm{L}$ of DNA template. Negative (Water for molecular biology; AmpliChem GmbH-An ITW Company, Darmstadt, Germany) and positive samples (DNA sample of $H$. contortus) were added in each PCR run. The PCR cycling program (Thermal cycler; SensoQuest GmbH, Göttingen, Germany) with 30 cycles followed Gharamah et al. (2012), Mangkit et al. (2014) and Vongnady et al. (2020). In each case, $5 \mu \mathrm{L}$ of each PCR product was added on $1 \%$ agarose gel stained with FluoroVue ${ }^{\mathrm{TM}}$ Nucleic Acid Gel Stain (SMOBIO Technology, Inc, Hsinchu City, Taiwan). The PCR products were run on $0.5 \times \mathrm{TBE}$ buffer using electrophoresis (Hoefer, Inc., Massachusetts, USA) for $45 \mathrm{~min}$ at $80 \mathrm{~V}$, and then the PCR products (321 bp) were compared with the DNA molecular marker (100 bp ladders) (Vivantis Technologies Sdn, Bhd, Selangor Darul Ehsan, Malaysia) and photographed using a gel documentation system (Omega Fluor and Omega Fluor Plus systems, Aplegen Inc., California, USA). All PCR products were purified and sequenced in both directions by Macrogen, Korea.

\section{Data analysis}

All randomly selected male Haemonchus spp. from goats distributed in three provinces each for Thailand and Lao PDR were identified as $H$. contortus based on the DF and synlophe patterns together with species confirmation from molecular analysis in some specimens. Morphological measurements and relevant data obtained from each morphological character of $H$. contortus were stored in a Microsoft Excel spreadsheet and some simple descriptive statistics were calculated. Most data were analyzed using $\mathrm{R}$ Studio version 3.6.1 to compare each character of $H$. contortus between two countries. Since all data were not normally distributed, the Wilcoxon Signed-Rank test, a non-parametric statistic was used. Significant difference was tested using a $\mathrm{p}$-value less than 0.05 . The ITS2 sequences at $231 \mathrm{bp}$ were aligned and blasted via the MEGA program version 7 (Kumar et al., 2016) while all DNA sequences from each country were grouped into genotypes. The polymorphisms of all genotypes in each country were compared with referent sequences of $H$. contortus (Accession number: X78803) and H. placei (Accession numbers: X78812, KF364623 and MH481601) in previous reports, and also the percentage 
identity of each genotype was determined using the BioEdit package (Hall, 1999). Phylogenetic analysis via the MEGA program version 7 of $H$. contortus genotypes from Thailand and Lao PDR including another sequence of $H$. contortus from various hosts in different countries (Accession numbers: AB908961: Lao PDR; EU086378, EU084691: United States; HQ389229: Iran; JX869066: the Czech Republic; JX901156: Tunisia; KJ724250, KJ724315: Pakistan; KP101363, KP101364: Thailand; KP090288, KP090290: Egypt; KC415117, KY305780: China; KF364629, KC632567, X78803: Australia; LC360146, LC360147: Bangladesh; MH481574, MH481598: Ghana) used the unweighted pair group method with arithmetic mean (UPGMA) method with a bootstrap of 1000 replications based on the Kimura-2 parameter model and was constructed by comparison with outgroups (H. placei).

\section{RESULTS}

Adult male Haemonchus spp. used in the current study were collected from the abomasa of goats in Thailand and Lao PDR. The proportion of Haemonchus spp. in goats accounted for $47.62 \%$ (30/63) and $66.02 \%$ $(68 / 103)$ in the three provinces sampled in each of Thailand and Lao PDR, respectively. All 255 adult male worms (85 worms/ province) were utilized for species identification based on the discriminant function (DF) and synlophe patterns (esophageal intestinal junction, EI and $4 \mathrm{~mm}$ from anterior end). The DF value and synlophe patterns in Thailand showed that $93.73 \%$ (239/255) of adult worms were identified as $H$. contortus and $5.88 \%(15 / 255)$ of male worms were classified as $H$. placei, while only one worm was a hybrid ( $\mathrm{DF}=0.63)$ (Table 1$)$. The cuticular ridges of $H$. contortus in the EI region revealed that $99.22 \%$ (253/255) of specimens were $H$. contortus presenting 30 ridges, while $0.78 \%$ (2/255) of specimens were unidentified ( 2 worms showing 29 ridges). At $4 \mathrm{~mm}$ from the anterior end, the synlophe patterns revealed that $98.43 \%$ (251/255) of worms showed 26 ridges and were recognized as $H$. contortus while $1.57 \%$ (4/255) of male worms were unidentified species having 27 ridges (Figure 3) and using both positions, $97.65 \%$ (249/255) of worms were $H$. contortus (Table 1 ). In Lao PDR, the DF value determined that $94.12 \%(240 / 255)$ of adult worms were identified as H. contortus and 5.10\% (13/255) of Haemonchus specimens were H. placei, while 2 worms were identified as hybrid ( $\mathrm{DF}=0.63$ ) (Table 1). The cuticular ridge patterns (Table 1) in the EI region showed that $99.22 \%(253 / 255)$ of specimens were $H$. contortus showing 30 ridges, with $0.78 \%$ (2/255) of worms not identified ( 2 worms had 29 ridges) while at $4 \mathrm{~mm}$ from the anterior end, the synlophe patterns indicated $97.65 \%$ (249/255) were $H$. contortus (showing 26 ridges) and 2.35\% (6/255) of worms were unknown species, showing 27 ridges (Figure 3 ), and examination at both positions identified $96.86 \%(247 / 255)$ of specimens as $H$. contortus. However, some specimens from both countries identified as $H$. placei $(\mathrm{DF}>0.63)$ and hybrids $(\mathrm{DF}=0.63)$ based on the DF results (Figure 4), including unclassified species based on cuticular patterns at both positions, were confirmed using the PCR method and sequencing (Tables 2 and 3). Then, all sequences that were blasted for a preliminary check with the Haemonchus spp. in the GenBank database were classified as $H$. contortus.

In total, 24 and 26 adult male $H$. contortus mentioned earlier in goats from Thailand (Table 2) and Lao PDR (Table 3) respectively, were confirmed using PCR based on ITS2 with specific bands at $321 \mathrm{bp}$. A $231 \mathrm{bp}$ of ITS2 sequences of $H$. contortus was used, and then was defined to six and ten distinct genotypes from original sequences in Thailand (Accession numbers: MT682914-MT682919) and Lao PDR (Accession numbers: MT682957-MT682966), respectively (Table 5). The sequence identity of genotypes derived from the $H$. contortus population ranged from 98.20 to $99.50 \%$ homology in each country. All genotypes in both countries were compared with reference sequences of $H$. contortus (Accession numbers: X78803, EU084691, KP101363) and the results indicated that sequence 


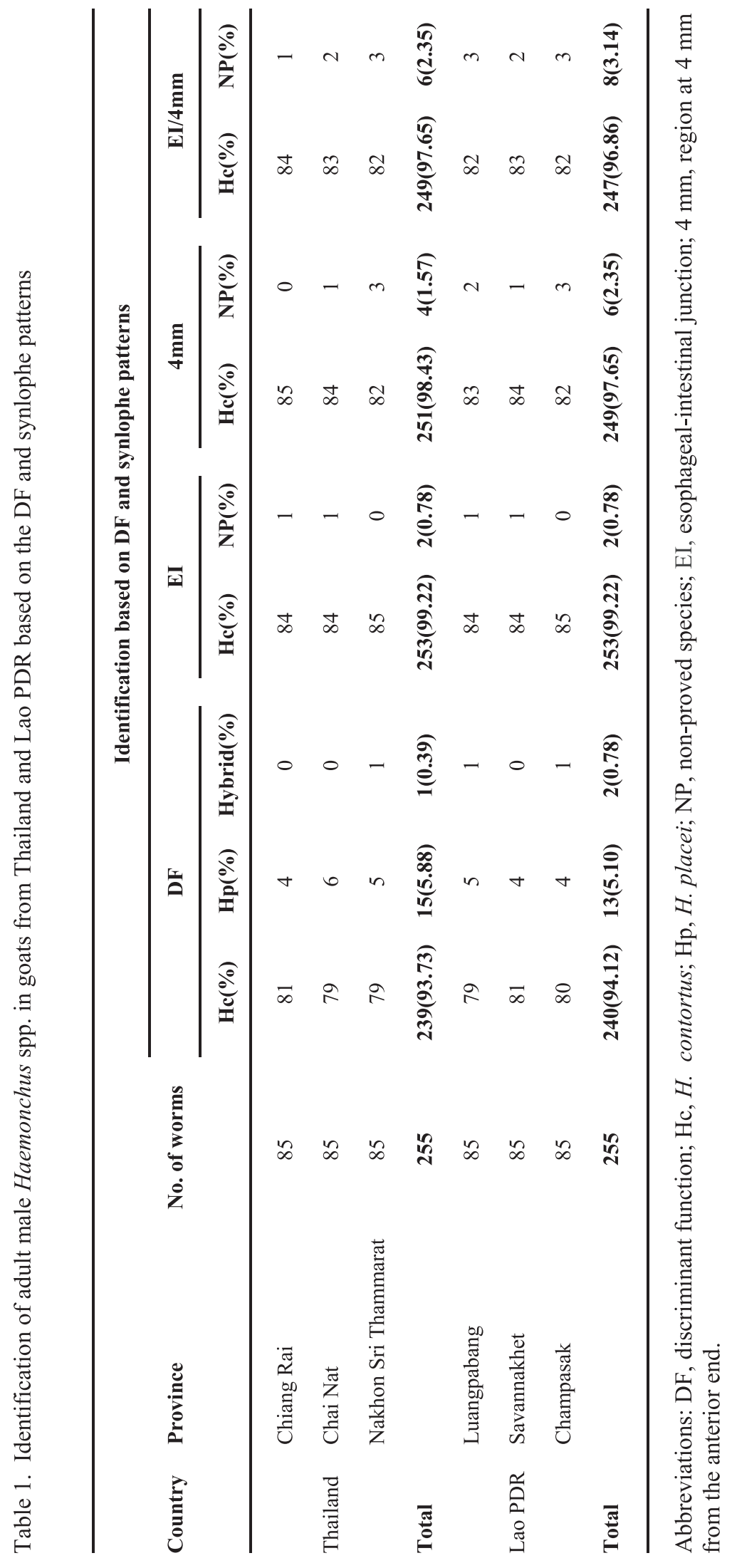




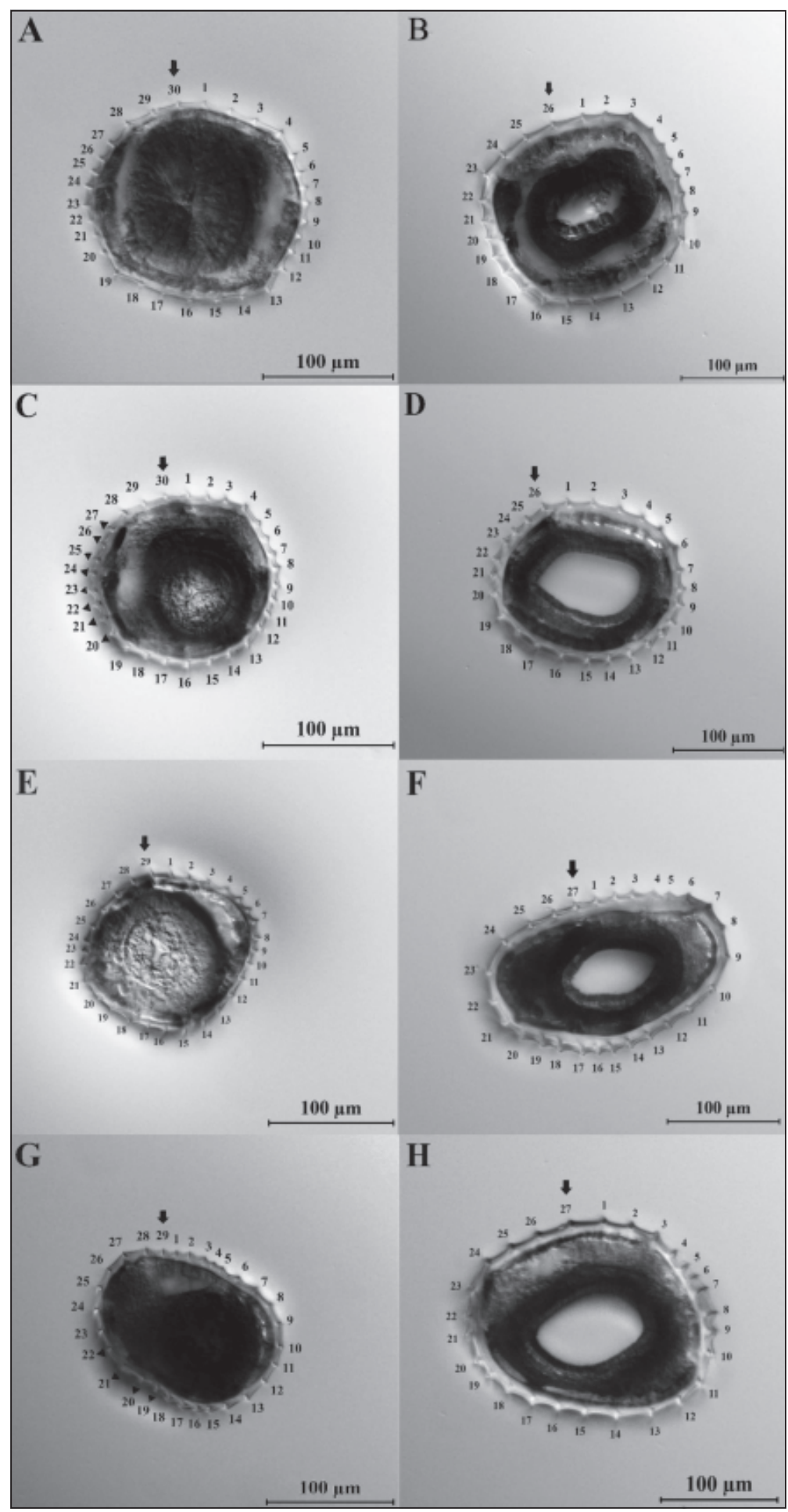

Figure 3. Synlophe patterns (cross section) of H. contortus in Thailand; (A) at esophageal intestinal junction, showing 30 ridges; (B) $4 \mathrm{~mm}$ region from the anterior end, showing 26 ridges; (E) esophageal intestinal junction, showing 29 ridges; (F) $4 \mathrm{~mm}$ region from the anterior end, showing 27 ridges, in Lao PDR; (C) esophageal intestinal junction, showing 30 ridges; (D) $4 \mathrm{~mm}$ region from the anterior end, showing 26 ridges; (G) esophageal intestinal junction, showing 29 ridges; (H) 4 mm region from the anterior end, showing 27 ridges. 


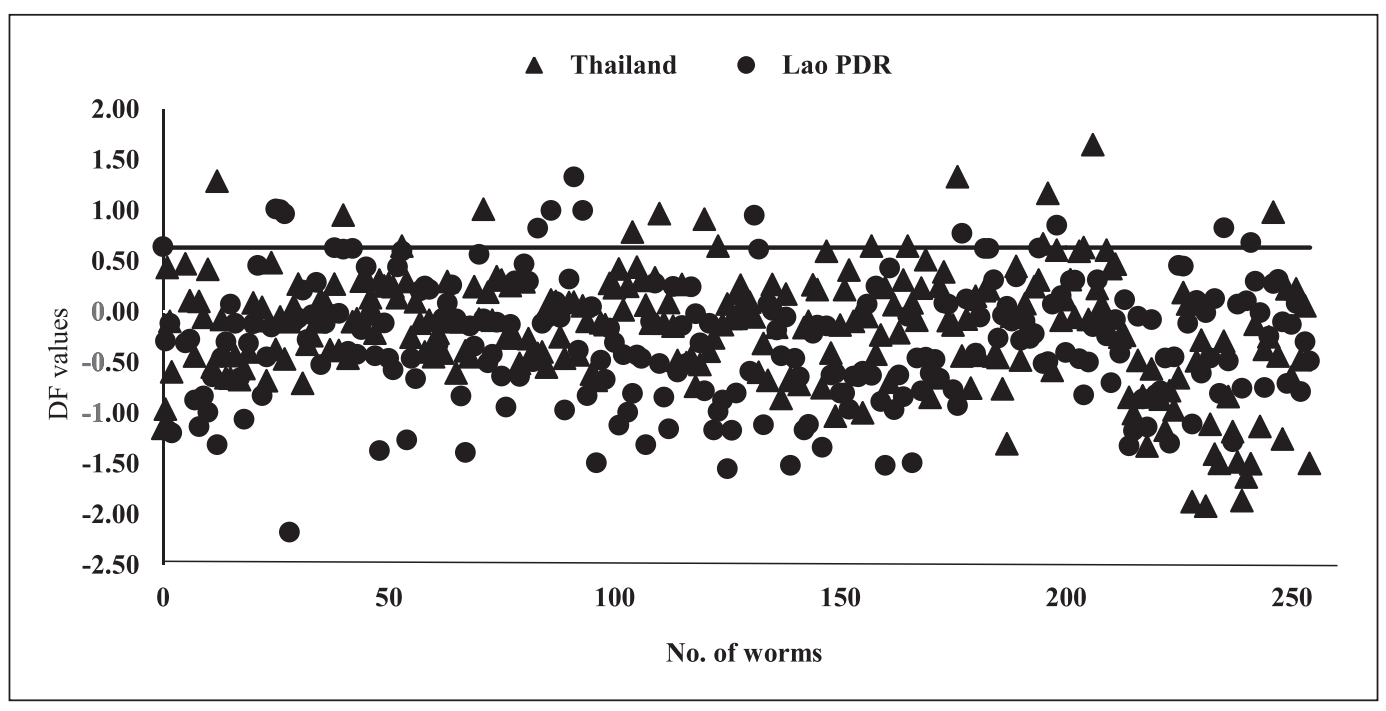

Figure 4. The value of discriminant function (DF) of individual adult male Haemonchus spp. in goats from Thailand and Lao PDR (dark black line, DF $=0.63$ ).

identities ranged from 98.20 to $100 \%$ homology in Thailand and from 97.80 to $100 \%$ homology in Lao PDR. In addition, these genotypes for each country were compared with the outgroup H. placei (Accession numbers: X78812, KF364623, MH481601). This comparison showed 96.10-98.70\% homology (Table 4). Moreover, the multiple alignments of six genotypes of $H$. contortus from Thailand compared with two sequence references (Accession numbers: X78803, KP101363) revealed six variable nucleotide positions: 10, 18, 21, 22, 123, and 196. Only two mutations (two: $\mathrm{T}<->\mathrm{C}$ ) were transition while four mutations were transversion (one: $\mathrm{C}<->\mathrm{A}$; two: $\mathrm{T}<->\mathrm{A}$; one: $\mathrm{C}<->\mathrm{G}$ ). In Lao PDR, the nucleotide polymorphism of the ten genotypes presented eight point mutations at positions 4, 10, 18, 21, 22, 55, 123 and 196. Five transversions (two: $\mathrm{C}<->\mathrm{A}$; two: $\mathrm{T}<->\mathrm{A}$; one: $\mathrm{C}<->\mathrm{G}$ ) and three transitions (three: $\mathrm{T}<->\mathrm{C}$ ) were detected. In addition, three main positions of genetic variations between $H$. contortus and H. place $i$ was detected at positions 24, 205, and 219 (Table 5). The phylogenetic tree based on UPGMA analyzed with $H$. contortus sequences from different hosts in several countries revealed that all genotypes of $H$. contortus from Thailand and Lao PDR were grouped into two main groups (Figure 5), and distinctly differed from the three reference sequences of $H$. place $i$ (Accession numbers: X78812, KF364623, MH481601) with a mean sequence identity of $97.09 \%$ homology. Group 1 comprised two genotypes from Thailand and three genotypes from Lao PDR as well as two sequences from Ghana. Group 2 was composed of four genotypes from Thailand and seven genotypes from Lao PDR which shared the same cluster with $H$. contortus from Egypt, China, Australia, Lao PDR, Thailand, Iran, Bangladesh, the Czech Republic, the United States, Pakistan, and Tunisia with a mean sequence identity of 98.77\% homology.

Morphometric data obtained from the 255 adult male $H$. contortus goats in the two countries were measured and compared. According to the Wilcoxon signed-rank test used, there were no significant differences in the mean and median length of cervical papillae, esophagus length, spicule length (right/left), spicule barb length (right), the synlophe patterns in the EI region (mean= 29.99 ridges, median=30 ridges) and $4 \mathrm{~mm}$ from the anterior end (mean=26.01 ridges for Thailand and 26.02 ridges for Lao PDR, median $=26$ ridges $)(p>0.05)$. However, there were significant differences in the body length, gubernaculum, and spicule barb length (left) between the $H$. contortus 


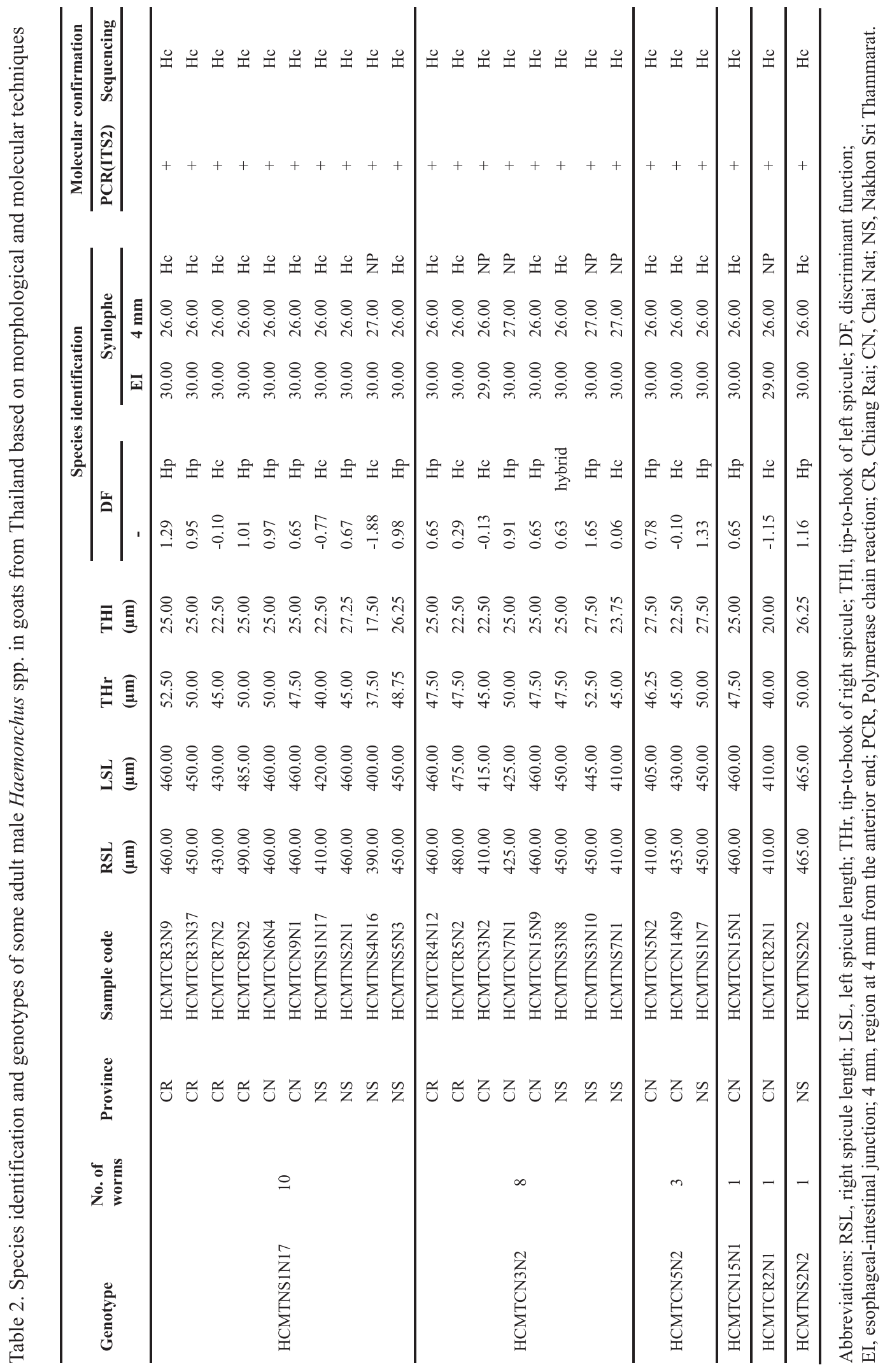




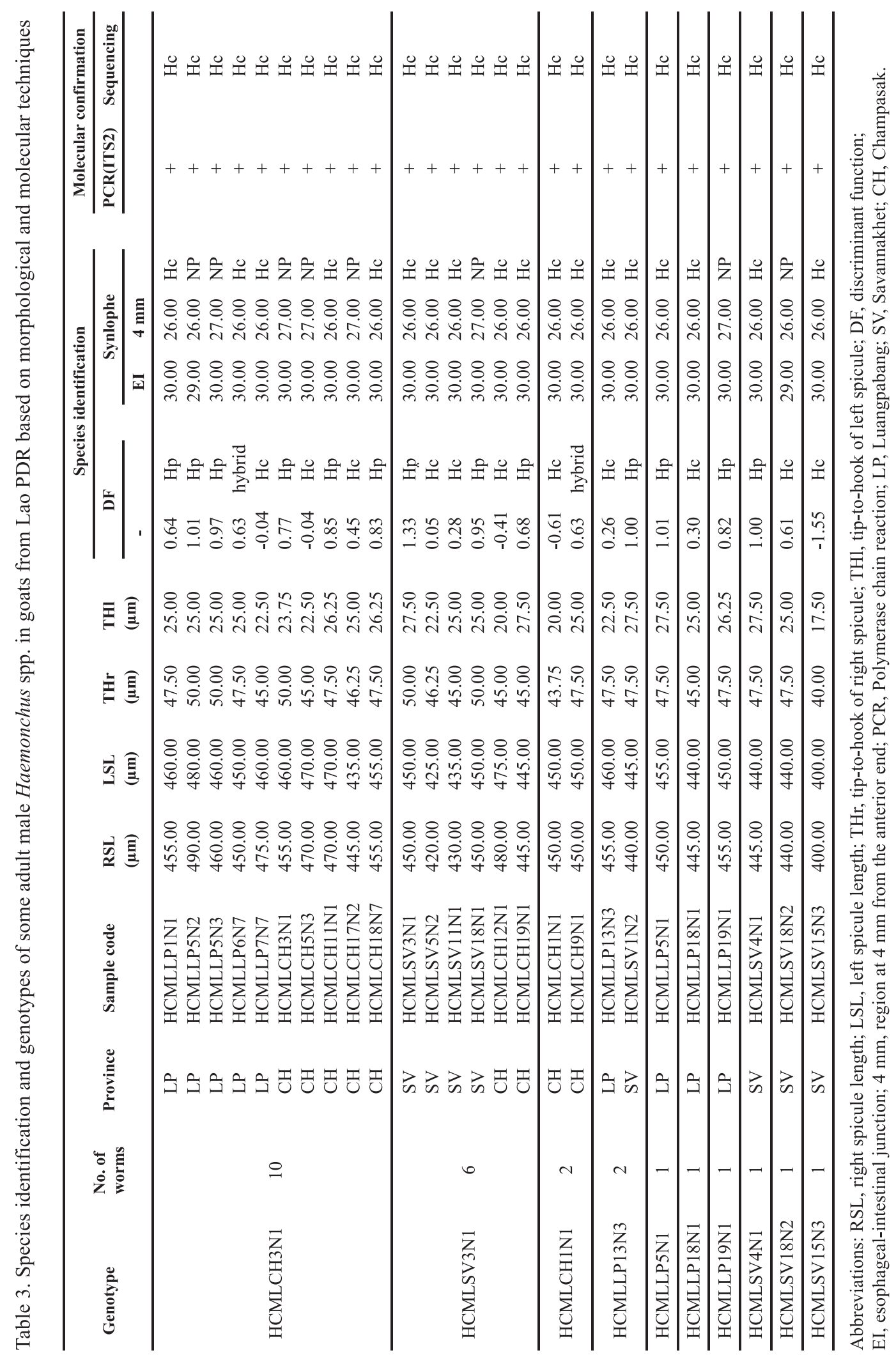




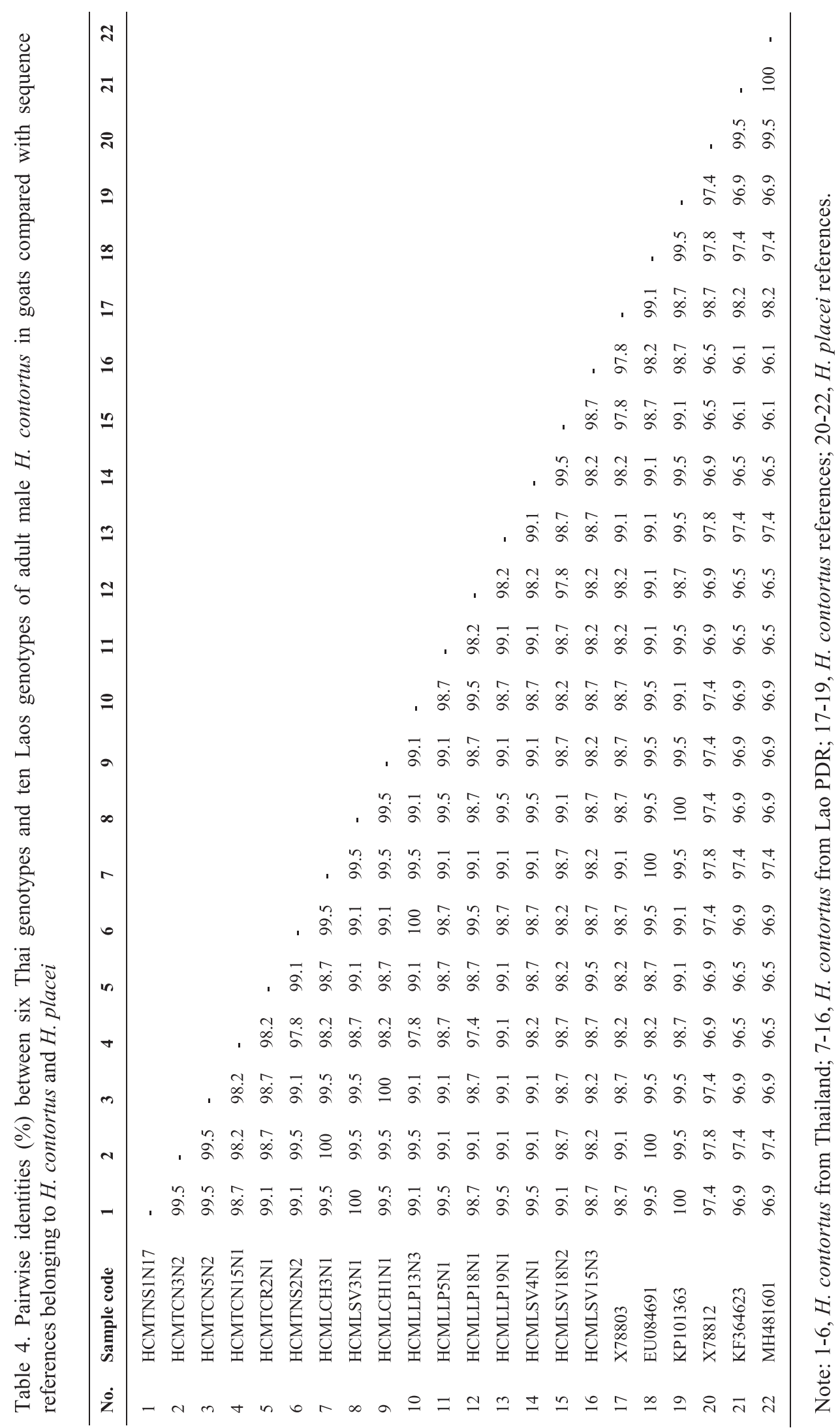




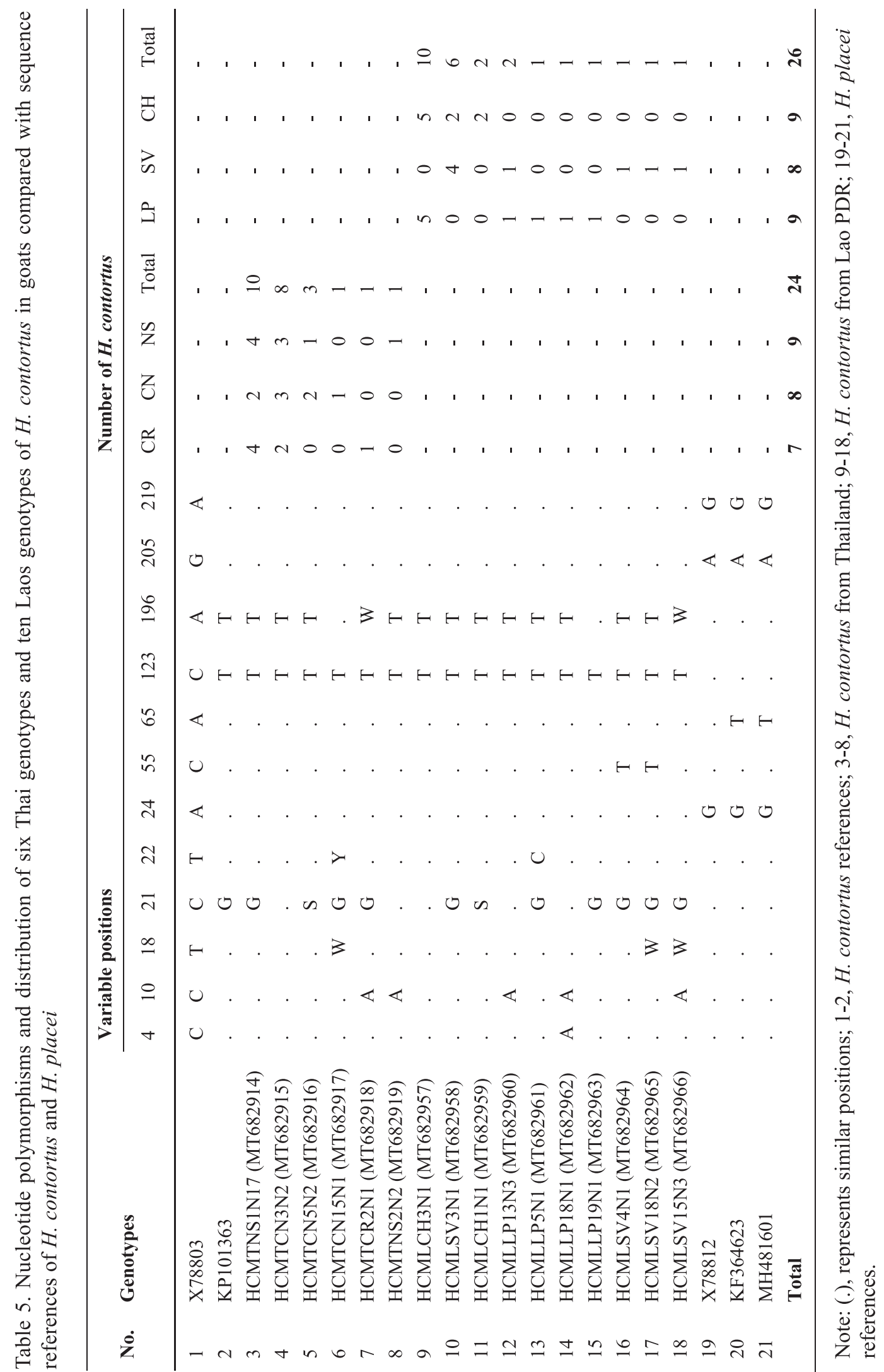




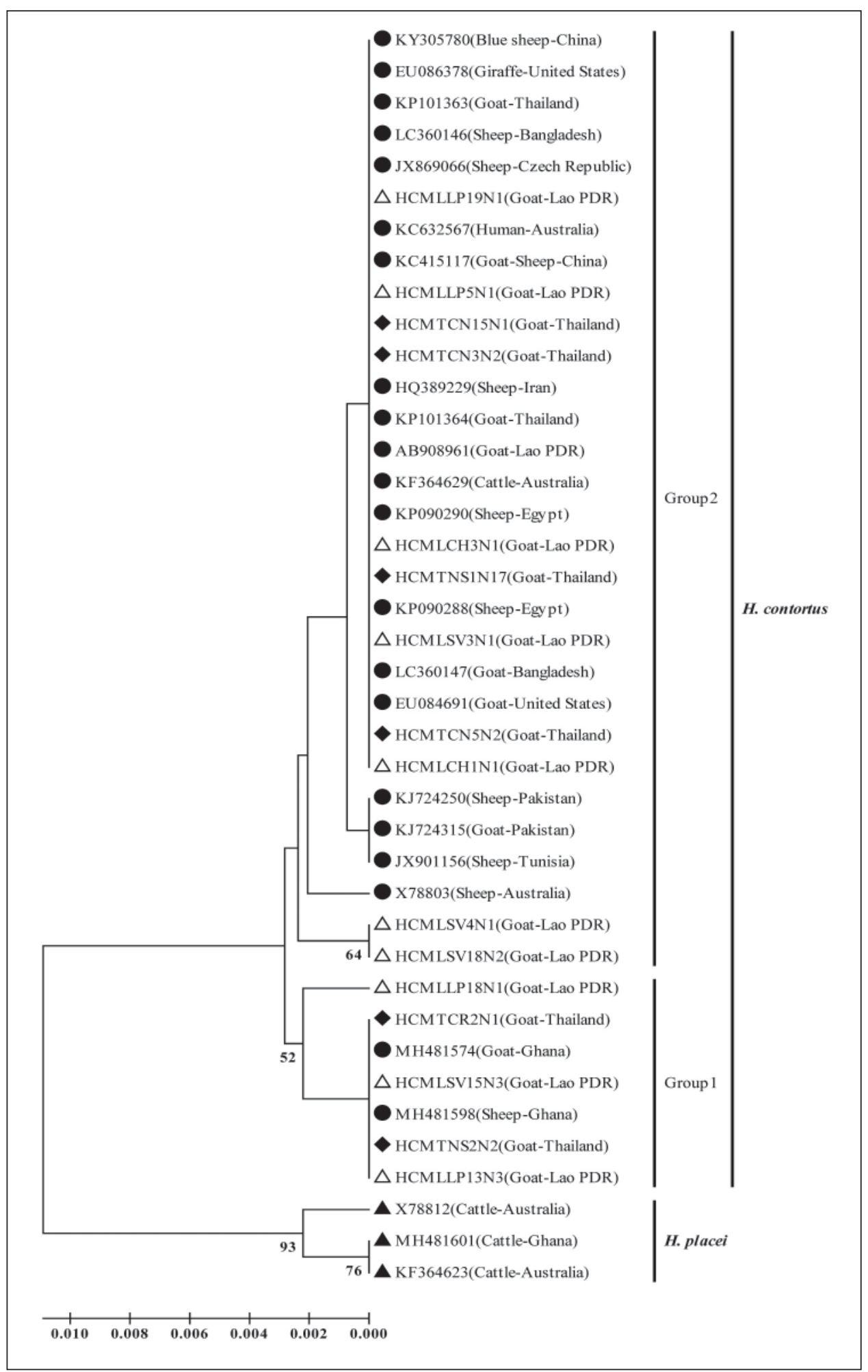

Figure 5. UPGMA analysis of $H$. contortus genotypes in goats from Thailand (six genotypes) and Lao PDR (ten genotypes) based on ITS2 comparison with sequences of $H$. contortus from different hosts in several countries together with H. placei (Accession numbers: X78812, KF364623, MH481601) as outgroups. 
Table 6. Morphological comparisons of adult male H. contortus in goats between Thailand and Lao PDR

\begin{tabular}{|c|c|c|c|c|c|c|c|c|}
\hline Characters & Country & $\mathbf{N}$ & Mean & SD & Median & Min-Max & $\mathbf{W}$ & p-value \\
\hline Body length & Thailand & 255.00 & 15.51 & 1.20 & 15.50 & $(12.50-18.00)$ & 27587.00 & $0.003 *$ \\
\hline$(\mathrm{mm})$ & Lao PDR & 255.00 & 15.24 & 1.32 & 15.00 & $(12.50-19.50)$ & & \\
\hline Cervical papillae & Thailand & 255.00 & 398.71 & 31.01 & 400.00 & $(310-470)$ & 32624.00 & 0.947 \\
\hline$(\mu \mathrm{m})$ & Lao PDR & 255.00 & 399.75 & 25.89 & 400.00 & $(330-465)$ & & \\
\hline Esophagus length & Thailand & 255.00 & 1295.98 & 107.86 & 1300.00 & $(1025-2375)$ & 33094.00 & 0.727 \\
\hline$(\mu \mathrm{m})$ & Lao PDR & 255.00 & 1305.18 & 98.94 & 1300.00 & $(1050-1600)$ & & \\
\hline Gubernaculum & Thailand & 255.00 & 214.53 & 11.40 & 210.00 & $(190-250)$ & 39145.00 & $0.000 *$ \\
\hline$(\mu \mathrm{m})$ & Lao PDR & 255.00 & 219.31 & 13.73 & 220.00 & $(190-260)$ & & \\
\hline Spicule length & Thailand & 255.00 & 430.08 & 21.18 & 430.00 & $(370-490)$ & 30799.00 & 0.301 \\
\hline$($ right $),(\mu \mathrm{m})$ & Lao PDR & 255.00 & 428.59 & 21.17 & 425.00 & $(375-490)$ & & \\
\hline Spicule length & Thailand & 255.00 & 428.96 & 21.11 & 430.00 & $(370-485)$ & 30884.00 & 0.326 \\
\hline (left), $(\mu \mathrm{m})$ & Lao PDR & 255.00 & 427.53 & 21.10 & 425.00 & $(380-480)$ & & \\
\hline Spicule barb & Thailand & 255.00 & 44.22 & 2.74 & 45.00 & $(36.25-52.50)$ & 29616.00 & 0.076 \\
\hline length (right), $(\mu \mathrm{m})$ & Lao PDR & 255.00 & 43.79 & 2.68 & 43.75 & $(37.50-50.00)$ & & \\
\hline Spicule barb & Thailand & 255.00 & 22.74 & 1.78 & 22.50 & $(15.00-27.50)$ & 27218.00 & $0.001 *$ \\
\hline length (left), $(\mu \mathrm{m})$ & Lao PDR & 255.00 & 22.24 & 2.15 & 22.50 & $(15.00-27.50)$ & & \\
\hline \multirow[t]{2}{*}{ Synlophe: EI } & Thailand & 255.00 & 29.99 & 0.09 & 30.00 & $(29-30)$ & 32513.00 & 0.999 \\
\hline & Lao PDR & 255.00 & 29.99 & 0.09 & 30.00 & $(29-30)$ & & \\
\hline \multirow[t]{2}{*}{ Synlophe: $4 \mathrm{~mm}$} & Thailand & 255.00 & 26.01 & 0.14 & 26.00 & $(25-27)$ & 32643.00 & 0.790 \\
\hline & Lao PDR & 255.00 & 26.02 & 0.27 & 26.00 & $(25-27)$ & & \\
\hline
\end{tabular}

Abbreviations: N, number of worms; SD, standard deviation; Min, minimum; Max, maximum; W, Wilcoxon signed-rank test; EI, esophagus intestinal junction; $4 \mathrm{~mm}$, region at $4 \mathrm{~mm}$ from the anterior end.

$*$ Difference is statistically significant at $\mathrm{p}<0.05$.

populations from Thailand and Lao PDR. The mean/median body length and left spicule barb length of this parasite from Thailand (mean $=15.51 \mathrm{~mm}$, median $=15.50 \mathrm{~mm}$; mean $=22.74 \mu \mathrm{m}$, respectively) were slightly longer than those observed in $H$. contortus from Lao PDR (mean=15.24 mm, median $=15$ $\mathrm{mm}$; mean $=22.24 \mu \mathrm{m}$, respectively) while the gubernaculum of $H$. contortus in Thailand (mean $=214.53 \mu \mathrm{m}$, median $=210 \mu \mathrm{m}$ was shorter than in $H$. contortus from Lao PDR (mean=219.31 $\mu \mathrm{m}$ median=220 $\mu \mathrm{m})$ $(\mathrm{p}<0.05)$ (Table 6).

\section{DISCUSSION}

Haemonchus spp. are blood sucking nematodes that cause a serious health problem for small ruminant production worldwide, particularly $H$. contortus that has been recovered from many parts of the world (Achi et al., 2003; Kumsa et al., 2008; Gharamah et al., 2012; Akkari et al., 2013; Yin et al., 2013; Shen et al., 2017; Kandil et al., 2017; Dey et al., 2019). Similarly, goats in Thailand and Lao PDR are now being raised in greater numbers, especially in smallholder form. Haemonchosis in goats caused by Haemonchus spp. is a continuous threaten with the current infection rate being $47.62 \%$ in Thailand and $66.02 \%$ in Lao PDR. Previously, postmortem and coproculture examination in Thailand and Lao PDR recorded high infection, accounting for 86.67\% (26/30) (Laosutthipong \& Eardmusic, 2019) and 69\% (Sato et al., 2014), respectively. This occurrence of Haemonchus spp. in these two tropical countries might be a consequence of suitable environmental 
conditions such as moisture and temperature to facilitate the complete life cycle as well as these parasites being well adapted to survive in unfavorable conditions such as drought and high temperature. Moreover, they also can develop rapidly against many types of anthelmintic drugs (Besier et al., 2016; Emery et al., 2016).

The discriminant function (DF) described by Jacquiet et al. (1997) and synlophe patterns described by Lichtenfels et al. (1994) were mainly applied to identify Haemonchus spp. in naturally infected goats in Thailand and Lao PDR. DF values based on the spicule and spicule barb lengths have been widely and successfully used to identify Haemonchus spp. (Achi et al., 2003; Gharamah et al., 2011; Santos et al., 2014; Vadlejch et al., 2014; Sambodo et al., 2018) since this is a rapidly and easily performed method (Jacquiet et al.,1997). Our findings also revealed that DF was able to identify a predominant species, $H$. contortus both in Thailand and Lao PDR, accounting for about $94 \%$. Only small proportions of specimens in Thailand (5.88\%) and Lao PDR (5.10\%) were classified as H. placei and hybrids (Table 1). However, all H. placei and hybrids were confirmed using PCR as $H$. contortus. Similarly, Vadlejch et al. (2014) revealed that three individual male $H$. place $i$ obtained from sheep identified by DF were proved as $H$. contortus using molecular techniques, and they suggested that the DF was not able to provide accurate identification of male Haemonchus spp. to the species level, while Santos et al. (2014) also found species misidentification of adult male Haemonchus spp. in sheep. These findings indicated that misidentification based on the DF is not uncommon, and other forms of morphological examination are required.

The synlophe patterns described by Lichtenfels et al. (1994) were also applied in the current research and proved to be one of the most useful diagnostic morphological characters to distinguish Haemonchus spp. (Lichtenfels et al., 1986; Lichtenfels et al., 1994; Vadlejch et al., 2014). Using synlophe patterns based on the number of ridges either at the esophageal intestinal junction (EI) or $4 \mathrm{~mm}$ from the anterior end or from both positions of Haemonchus spp. in goats from Thailand and Lao PDR, about 97-99\% were identified as $H$. contortus, showing 30 ridges and 26 ridges, respectively, while synlophe patterns in the EI region seemed to be more reliable resulting in $99 \%$ of $H$. contortus being identified. These results were based on Lichtenfels et al. (1994) and Silva et al. (2015) who reported the position in the EI region had 30 ridges and Rahman \& Abd Humid (2007) reported that the region at 4 $\mathrm{mm}$ from the anterior end had 26 ridges in goats. However, 24 ridges for $H$. contortus at position $4 \mathrm{~mm}$ from the anterior end were also recorded in sheep (Rahman \& Abd Humid, 2007) while Lichtenfels et al. (1994) reported 25 ridges; thus the synlophe patterns at this position of $H$. contortus varied somewhat between 24, 25, and 26 ridges. This variation in the cuticular ridge patterns of male $H$. contortus also occurred at similar positions in both countries; for example, in the EI region, the synlophe patterns presented 29 ridges, while variations in ridge number at $4 \mathrm{~mm}$ from the anterior end showed only 27 ridges in both countries. A closely related species, $H$. placei including $H$. similis showed synlophe patterns in the EI region for both these species having 34 ridges (Lichtenfels et al., 1994; Silva et al., 2015) and synlophe patterns at $4 \mathrm{~mm}$ from the anterior end of $H$. place $i$ and $H$. similis presented 30 ridges (Lichtenfels et al., 1994). Therefore, our observations of varied ridge numbers for $H$. contortus at both positions were not consistent with the synlophe references regarding $H$. place $i$ and $H$. similis.

However, all synlophe pattern variations mentioned above were properly resolved using PCR, and then identified as $H$. contortus, and we assumed that all 255 male Haemonchus spp. in each country were $H$. contortus. Therefore, the number of possible cuticular ridge patterns of $H$. contortus in the present study from both countries ranged from 29 to 30 ridges in the EI region and from 26 to 27 ridges at $4 \mathrm{~mm}$ from the anterior end, while the mean/median ridge numbers at both positions between two countries were not significantly different ( $p>0.05$ ) (Table 6). These variable cuticular ridges in the current 
study might occur naturally depending on many factors such as hosts and the area of study, as Rahman \& Abd Humid (2007) reported synlophe patterns in the region $4 \mathrm{~mm}$ from the anterior end in goats and sheep in Malaysia with 26 and 24 ridges, respectively.

Molecular diagnosis based on the ITS2 region is commonly used as a molecular marker for specific identification of strongylid worms because of its low intra-variation (Heise et al., 1999; Gasser \& Newton, 2000). According to our genetic data analysis as well as the phylogenetic tree based on UPGMA, all proved specimens (including four and eight randomly selected $H$. contortus from Thailand and Lao PDR, respectively identified clearly by their DF and synlophe patterns) from Thailand (Table 2) and Lao PDR (Table 3) were classified as a mono species, $H$. contortus. To provide accuracy for the identification of this species, some supporting evidences demonstrated that $H$. contortus was differentiated from a closely relate species, $H$. place $i$ by the different nucleotide bases at positions 24, 205 and 219. These three positions were only found in $H$. place $i$ and never presented in $H$. contortus, which was in agreement with previous reports in Bangladesh (Dey et al., 2019), Thailand (Mangkit et al., 2014), and the Czech Republic (Vadlejch et al., 2014). Moreover, the nucleotide difference at position 24 also is known as a restriction site of $B f a \mathrm{I}$ of $H$. place $i$, being can be used as a diagnostic marker to differentiate $H$. placei from $H$. contortus (Stevension et al., 1995). In addition, the mean sequences identity of $H$. contortus in goats between the two countries showed $98.97 \%$ homology, compared with 97\% homology for H. placei in Thailand and 96.86\% homology in Lao PDR. The UPGMA method on a global scale is well supported and this method in the current study demonstrated that all genotypes of $H$. contortus from Thailand and Lao PDR were grouped in the same clade with $H$. contortus from various hosts in different countries with $98.77 \%$ homology, and were also clearly distinguished from $H$. placei with $97.09 \%$ homology on average. These features are consistent with some reports in Thailand
(Mangkit et al., 2014; Laosutthipong \& Eardmusic, 2019) and in Bangladesh (Dey et al., 2019). Interestingly, we also found that there were some genotypes of $H$. contortus that shared their genetic information between the two countries that might have been a consequence of infected host movement through Thailand-Laos border crossing points from the past and ongoing in the present. Therefore, based on the DF combined with synlophe patterns and supporting genetic data analysis using the UPGMA method, we assumed that all selected randomly specimens obtained from goats in Thailand and Lao PDR were the highly pathogenic nematode, $H$. contortus.

Significant morphological differences of H. contortus between Thailand and Lao PDR in the recent study were found in the body length, gubernaculum, and the left spicule barb length (Table 6). These differences might be associated with some specific factors, namely the area of study, diet, age of host, and parasite intensity (Kuchai et al., 2012) including the effect of fixative agent (ethanol) on the body of the parasite (Jacquite et al., 1997). Our findings indicated that the mean body length and other structure lengths of male $H$. contortus from both countries were varied somewhat compared with the findings of other researchers in previous investigations depending on the location of the study and the hosts, such as in ruminants in North America (Lichtenfels et al.,1994), in goats and sheep in Malaysia (Rahman \& Abd Humid, 2007; Gharamah et al., 2011; Gharamah et al., 2014), in sheep in Egypt (Badawy et al., 2015), in goats in Indonesia (Sambodo et al., 2018), and in sheep in Brazil (Santos et al., 2014). However, most researchers recommended using the spicule and barb lengths as some of the most useful morphological characters for classifying Haemonchus spp. in ruminants (Jacquiet et al., 1997; Achi et al., 2003; Kumsa et al., 2008; Gharamah et al., 2011; Gharamah et al., 2014). In fact, our observations based on these characters of some individual $H$. contortus from Thailand and Lao PDR were not all within the ranges for $H$. contortus described by Lichtenfels et al. (1994), and some specimens 
also overlapped in length with other species except for the spicule and barb lengths of $H$. similis, a parasite of cattle, that were distinguished clearly. In contrast, considering the mean lengths of the right and left spicule and barbs of $H$. contortus in the current study, there were minor differences from the mean length of the spicule (425 $\mu \mathrm{m})$ and right $(42 \mu \mathrm{m}) /$ left $(22 \mu \mathrm{m})$ barbs of $H$. contortus as referenced by Lichtenfels $e t$ al. (1994). As mentioned above, overlapping measurements of spicule and barb lengths including other structure lengths based on the individual worms in the current study were also consistent with some researchers, namely Lichtenfels et al. (1994), Santos et al. (2014), and Vadlejch et al. (2014), especially for the two main species, $H$. contortus and H. placei. Our study suggested that the use of these spicule and barb lengths may influence species identification and lead to misclassification in some samples. This is in agreement with Silva et al. (2015) who revealed that overlapping measurements occurred in the body length of some female worms, making this parameter are less valuable for identifying Haemonchus spp. However, the current observations revealed that applying spicule and barb lengths via the DF formula might be a better approach, while synlophe patterns and possibly molecular methods should be combined.

\section{CONCLUSION}

The present study was the first morphological identification of adult male Haemonchus spp. in goats raised in different regions of Thailand and Lao PDR using the discriminant function (DF) and synlophe patterns at the esophageal intestinal junction (EI) and at $4 \mathrm{~mm}$ from the anterior end. This research revealed the DF and synlophe patterns to be useful tools, particularly the synlophe patterns for identifying Haemonchus spp. and further subclassification to $H$. contortus. The synlophe patterns in the EI region seemed to be more promising than at $4 \mathrm{~mm}$ from the anterior end for identifying Haemonchus spp. Therefore, the use of the DF combined with synlophe patterns increased the accuracy of identifying Haemonchus spp. using a lowcost diagnostic device, and also provided invaluable epidemiological data on these parasites of goats in Thailand and Lao PDR, where advanced techniques and large budgets are not available in endemic areas. However, in some specimens, molecular techniques are also required.

Acknowledgments. The authors thank Prof. Dr. Sathaporn Jittapalapong, the Dean of the Faculty of Veterinary Technology, Kasetsart University, Thailand and Dr. Somphong Chanthavong, the Dean of the Faculty of Agriculture and Envelopment, Savannakhet University, Lao PDR for providing support with all relevant facilities to conduct this research. We are grateful to the goat farmers both Thailand and Lao PDR and to Mr. Soukvilay Yomsamon and Mr. Xaykham Onphachan for their help in sample collection. We also acknowledge the assistance of the relevant technical staff at both Faculties. We also thank Asst. Prof. Dr. Mereerat Manwong, College of Medicine and Public Health Ubon Ratchathani University, Thailand for valuable advice in statistical data analysis, and we would like to thank Dr. Andrew Warner (an Australian), Kasetsart University Research and Development Institute, Kasetsart University, Bangkok, Thailand to assist in English editing of the manuscript.

\section{Funding}

This work was financially supported by a Kasetsart University Scholarship for ASEAN for Commemoration of the $60^{\text {th }}$ Birthday Anniversary of Professor Dr. Her Royal Highness Princess Chulabhorn Mahidol.

\section{Ethics approval}

This research was approved by the Kasetsart University Institutional Animal Care and Committee Use with the approval no. ACKU62-VTN-006, Kasetsart University, Thailand.

\section{Conflict of interests}

The authors declare no conflict of interest. 


\section{REFERENCES}

Achi, Y.L., Zinsstag, J., Yao, K., Yeo, N., Dorchies, P. \& Jacquiet, P. (2003). Host specificity of Haemonchus spp. for domestic ruminants in the savanna in northern Ivory Coast. Veterinary Parasitology 116(2): 151-158.

Akkari, H., Gharbi, M., Awadi, S., Mohamed, A.D. \& Kumsa, B. (2013). New sublinguiform vulvar flap of Haemonchus species in naturally infected domestic ruminants in Béja Abattoir, North Tunisia. Veterinarski Arhiv 82(4): 281-291.

Amarante, A.F.T. (2011). Why is it important to correctly identify Haemonchus species?. Revista Brasileira de Parasitologia Veterinária 20(4): 263-268.

Badawy, A.I.I., Alzohairy, A.M., Abdel-Aziz, A., Abou El-Nour, M.F. \& Elsayed, A.N. (2015). Morphological and molecular characterization of Haemonchus contortus (Rudolphi, 1803) Cobb, 1898 (Nematoda: Trichostrongyloidea) from sheep, Ovis aries in Egypt based on the second internal transcribed spacer of ribosomal DNA. International Journal of Advanced Research 3(5): 1152-1161.

Besier, R.B., Kahn, L.P., Sargison, N.D. \& Van Wyk, J.A. (2016). The Pathophysiology, Ecology and Epidemiology of Haemonchus contortus Infection in Small Ruminants. Advances in Parasitology 93: 95-143.

Comes, A.M., Humbert, J.F., Cabaret, J. \& Elard, L. (1996). Using molecular tools for diagnosis in veterinary parasitology. Veterinary Research 27(4-5): 333-342.

Dey, A.R., Zhang, Z., Begum, N., Alim, M.A., Hu, M. \& Alam, M.Z. (2019). Genetic diversity patterns of Haemonchus contortus isolated from sheep and goats in Bangladesh. Infection, Genetics and Evolution 68: 177-184.

Emery, D.L., Hunt, P.W. \& Le Jambre, L.F. (2016). Haemonchus contortus: the then and now, and where to from here? International Journal for Parasitology 46(12): 755-769.
Gasser, R.B. \& Newton, S.E. (2000). Genomic and genetic research on bursate nematodes: significance, implications and prospects. International Journal for Parasitology 30(4): 509-534.

Gharamah, A.A., Azizah, M.N. \& Rahman, W.A. (2012). Genetic variation of Haemonchus contortus (Trichostrongylidae) in sheep and goats from Malaysia and Yemen. Veterinary Parasitology 188(3-4): 268276.

Gharamah, A.A., Rahman, W.A. \& Azizah, M.S. (2014). Morphological variation between isolates of the nematode Haemonchus contortus from sheep and goat populations in Malaysia and Yemen. Journal of Helminthology 88(1): 82-88.

Gharamah, A.A., Rahman, W.A. \& Nor, S.A.M. (2011). Phenotypic differences of Haemonchus contortus from sheep and goats in the States of Perak and Kelantan, Peninsular Malaysia. Acta Parasitologica 56(4): 412-417.

Hall, T.A. (1999). BioEdit: A user-friendly biological sequence alignment editor and analysis program for Windows 95/ 98/NT. Nucleic Acids Symposium Series 41: 95-98.

Heise, M., Epe, C. \& Schnieder, T. (1999). Differences in the second internal transcribed spacer (ITS-2) of eight species of gastrointestinal nematodes of ruminants. Journal of Parasitology 85(3): 431-435.

Hoberg, E.P., Lichtenfels, J.R. \& Gibbons, L. (2004). Phylogeny for species of Haemonchus (Nematoda: Trichostrongyloidea): considerations of their evolutionary history and global biogeography among Camelidae and Pecora (Artiodactyla). Journal of Parasitology 90(5): 1085-1102.

Jacquiet, P., Cabaret, J., Cheikh, D. \& Thiam, E. (1997). Identification of Haemonchus species in domestic ruminants based on morphometrics of spicules. Parasitology Research 83(1): 82-86. 
Jacquiet, P., Humbert, J.F., Comes, A.M., Cabaret, J., Thiam, A. \& Cheikh, D. (1995). Ecological, morphological and genetic characterization of sympatric Haemonchus spp. parasites of domestic ruminants in Mauritania. Parasitology 110(Pt 4): 483-492.

Kandil, O.M., Abdelrahman, K.A., Fahmy, H.A., Mahmoud, M.S., El Namaky, A.H. \& Miller, J.E. (2017). Phylogenetic patterns of Haemonchus contortus and related trichostrongylid nematodes isolated from Egyptian sheep. Journal of Helminthology 91(5): 583-588.

Kuchai, J.A., Ahmad, F., Chishti, M.Z., Tak, H., Ahmad, J., Ahmad, S. \& Rasool, M. (2012). A study on morphology and morphometry of Haemonchus contortus. Pakistan Journal of Zoology 44(6): 1737-1741.

Kumar, S., Stecher, G. \& Tamura, K. (2016). MEGA7: Molecular evolutionary genetics analysis version 7.0 for bigger datasets. Molecular Biology and Evolution 33: 1870-1874.

Kumsa, B., Tolera, A. \& Abebe, R. (2008). Vulvar morphology and sympatry of Haemonchus species in naturally infected sheep and goats of Ogaden region, eastern Ethiopia. Veterinarski Arhiv 78: 331-342.

Laosutthipong, C. \& Eardmusic, S. (2019). Genetic characterization of Haemonchus contortus from slaughtered goats in Cha-am district, Phetchaburi province, Thailand. Songklanakarin Journal of Science and Technology 41: 81-88.

LeJambre, L.F. \& Whitlock, J.H. (1968). Seasonal fluctuation in linguiform morphs of Haemonchus contortus cayugensis. Parasitology 54(4): 827-830.

Lichtenfels, J.R. \& Pilitt, P.A. 2000. Synlophe patterns of the haemonchinae of ruminants (Nematoda: Trichostrongyloidea). Journal of Parasitology 86(5): 1093-1098.
Lichtenfels, J.R., Pilitt, P.A. \& Hoberg, E.P. (1994). New morphological characters for identifying individual specimens of Haemonchus spp. (Nematoda: Trichostrongyloidea) and a key to species in ruminants of North America. Journal of Parasitology 80(1): 107-119.

Lichtenfels, J.R., Pilitt, P.A. \& LeJambre, L.F. (1986). Cuticular ridge patterns of Haemonchus contortus and Haemonchus placei (Nematoda: Trichostrongyloidea). Proceedings of the Helminthological Society of Washington 53(1): 94-101.

MAFF (Ministry of Agriculture, Fisheries and Food). (1971). Manual of Veterinary Parasitological Laboratory Techniques, London: HM Stationery Oce.

Mangkit, B., Thaenkham, U., Adisakwattana, P., Watthanakulpanich, D., Jantasuriyarat, C. \& Komalamisra, C. (2014). Molecular Characterization of Haemonchus contortus (Nematoda: Trichostrongylidae) from small ruminants in Thailand based on the second internal transcribed spacer of ribosomal DNA. Kasetsart Journal (Natural Science) 48(5): 740-758.

Pralomkarn, W. \& Boonsanit, D. (2012). Knowledge in goats in Thailand. Walailak Journal of Science and Technology 9(2): 93-105.

Rahman, W.A. \& Abd Hamid, S. (2007). Morphological characterization of Haemonchus contortus in goats (Capra hircus) and sheep (Ovis aries) in Penang, Malaysia. Tropical Biomedicine 24(1): 23-27.

Roeber, F., Jex, A.R., Campbell, A.J., Campbell, B.E., Anderson, G.A. \& Gasser, R.B. (2011). Evaluation and application of a molecular method to assess the composition of strongylid nematode populations in sheep with naturally acquired infections. Infection, Genetics and Evolution 11(5): 849-854. 
Salle, G., Doyle, S.R., Cortet, J., Cabaret, J., Berriman, M., Holroyd, N. \& Cotton, J.A. (2019). The global diversity of Haemonchus contortus is shaped by human intervention and climate. Nature Communications 10(1): 4811.

Sambodo, P., Prastowo, J., Indarjulianto, S. \& Kurniasih, K. (2018). Morphology and morphometry of Haemonchus contortus in goats in Yogyakarta, Indonesia. Jurnal Kedokteran Hewan 12(3): 62-65.

Santos, M.C., Amarante, M.R., Silva, M.R. \& Amarante, A.F. (2014). Differentiation of Haemonchus placei from Haemonchus contortus by PCR and by morphometrics of adult parasites and third stage larvae. Revista Brasileira de Parasitologia Veterinária 23(4): 495-500.

Sato, M.O., Sato, M., Chaisiri, K., Maipanich, W., Yoonuan, T., Sanguankiat, S., Pongvongsa, T., Boupha, B., Moji, K. \& Waikagul, J. (2014). Nematode infection among ruminants in monsoon climate (Ban-Lahanam, Lao PDR) and its role as food-borne zoonosis. Revista Brasileira de Parasitologia Veterinária 23(1): 8084.

Shen, D.D., Wang, J.F., Zhang, D.Y., Peng, Z.W., Yang, T.Y., Wang, Z.D., Bowman, D.D., Hou, Z.J. \& Liu, Z.S. (2017). Genetic diversity of Haemonchus contortus isolated from sympatric wild blue sheep (Pseudois nayaur) and sheep in Helan mountains, China. Parasites \& Vectors 10(1): 437.

Silva, M.R., Amarante, M.R., Bresciani, K.D. \& Amarante, A.F. (2015). Host-specificity and morphometrics of female Haemonchus contortus, $H$. place $i$ and $H$. similis (Nematoda: Trichostrongylidae) in cattle and sheep from shared pastures in Sao Paulo State, Brazil. Journal of Helminthology 89(3): 302-306.

Soulsby, E.J.L. (1982). Helminthes, arthropods and protozoa of domesticated animals, $7^{\text {th }}$ edition. London: Bailliere Tindall.

Stevenson, L.A., Chilton, N.B. \& Gasser, R.B. (1995). Differentiation of Haemonchus placei from $H$. contortus (Nematoda: Trichostrongylidae) by the ribosomal DNA second internal transcribed spacer. International Journal for Parasitology 25(4): 483-488.
Troell, K., Tingstedt, C. \& Hoglund, J. (2006). Phenotypic characterization of Haemonchus contortus: a study of isolates from Sweden and Kenya in experimentally infected sheep. Parasitology 132(Pt 3): 403-409.

Vadlejch, J., Lukesova, D., Vasek, J., Vejl, P., Sedlak, P., Cadkova, Z., Langrova, I., Jankovska, I. \& Salaba, O. (2014). Comparative morphological and molecular identification of Haemonchus species in sheep. Helminthologia 51(2): 130-140.

Valderrabano, J., Delfa, R. \& Uriarte, J. (2002). Effect of level of feed intake on the development of gastrointestinal parasitism in growing lambs. Veterinary Parasitology 104(4): 327-338.

Vongnady, K., Rucksaken, R. \& Mangkit, B. (2020). Morphological characters for identifying adult female Haemonchus species (Nematoda: Trichostrongyloidea) in naturally infected goats in Thailand. The 50 $0^{\text {th }}$ National Graduate Research Conference: 1146-1173.

Waller, P.J. \& Chandrawathani, P. (2005). Haemonchus contortus: parasite problem No. 1 from tropics-Polar Circle. Problems and prospects for control based on epidemiology. Tropical Biomedicine 22(2): 131-137.

Waller, P.J., Rudby-Martin, L., Ljungstrom, B.L. \& Rydzik, A. (2004). The epidemiology of abomasal nematodes of sheep in Sweden, with particular reference to over-winter survival strategies. Veterinary Parasitology 122(3): 207-220.

Wang, C., Li, F., Zhang, Z., Yang, X., Ahmad, A.A., Li, X., Du, A. \& Hu, M. (2017). Recent research progress in China on Haemonchus contortus. Frontiers in Microbiology 8: 1509.

Yin, F., Gasser, R.B., Li, F., Bao, M., Huang, W., Zou, F., Zhao, G., Wang, C., Yang, X., Zhou, Y., Zhao, J., Fang, R. \& Hu, M. (2013). Genetic variability within and among Haemonchus contortus isolates from goats and sheep in China. Parasites \& Vectors 6(1): 279 . 